\title{
A Teologia Latino Americana como Teologia Prática, em diálogo com Henri Bourgeois
}

\author{
The American Latin Theology as Practical Theology, \\ in dialogue with Henri Bourgeois
}

Alzirinha Souza

\section{Resumo}

A primeira novidade deste artigo está na apresentação da argumentação histórico-teológico-metodológico para a afirmação da TdLib, como TPr. Com efeito, a Teologia Prática, como a originada no norte da Europa e pensada em contexto francês, é ainda recente no contexto latino-americano.

A segunda está na apresentação do autor francês Henri Bourgeois (19342002). Bourgeois associa duas características essenciais em sua obra: é um dos representantes da TPr francesa e profundo conhecedor de sua constituição e fazer teológico e conhece, na prática e na teoria, a TdLib. Conjugadas essas duas vertentes, encontramos em seu pensamento os critérios de definição para que uma teologia seja efetivamente considerada como TPr e qual foi, a partir da perspectiva metodológica, a contribuição da Teologia da Libertação à Teologia Prática francesa.

Para tanto, organizamos nosso texto em três partes. A primeira tratará dos principais dados bibliográficos e teológicos de Bourgeois. Na segunda parte apresentamos os elementos metodológicos da TdLib, para finalmente na terceira parte, apresentarmos a articulação teológica entre as duas correntes teológicas.

Palavras-chave: Henri Bourgeois. Teologia da Libertação. Teologia Prática Francesa. Método. Articulação Teológica. 


\begin{abstract}
The first novelty lies in the presentation of the historical, theological and methodological arguments on asserting the Liberation Theology as Practical Theology. Indeed, the Practical Theology, as that one originated in northern Europe, and thought in the French context, it is still new in the Latin American context.
\end{abstract}

The second novelty is the presentation of the French author Henri Bourgeois (1934-2002). Bourgeois joins two essential characteristics in his work: he is one of the representatives of the French Practical Theology and deep connoisseur of its theological formation and doing, beyond the fact that he knows, in practice and theory, the Liberation Theology. Combining these two aspects, we find in his thought the defining criteria for a Theology to be considered effectively as Practical Theology, and, taking into consideration the methodological perspective, what was the contribution from the Liberation Theology to the French Practical Theology.

Therefore, we organized our text into three parts. The first part will deal with main bibliographic and theological data regarding Bourgeois. In the second part, we presented the methodological elements of the Liberation Theology, so that, finally in the third part, we present the theological linking between the two theological currents/trends.

Keywords: Henri Bourgeois. Liberation Theology. French Practical Theology. Methods. Theological Linking.

\title{
Introdução
}

A constituição da Teologia Prática (TPr) Francesa passa por dois momentos marcantes: o primeiro é marcado pela reflexão inicial das diferenças entre ambas a partir das publicações dos artigos de André P. Liège ao final dos anos 50. O segundo se dá nos anos 60/70 com a efetiva utilização das ciências humanas e sociais no fazer teológico. O conhecimento concreto das realidades permitiu à teologia oferecer respostas às demandas da realidade extra-eclesial.

Nascida na Alemanha, onde assume um caráter mais empírico, a TPr acentua nos países francófonos o caráter mais prático de proximidade com a realidade e não apenas a sua leitura. Efetivamente indutiva e ligada às transformações sociais que se apresentavam nos anos pós-conciliares, 
especialmente em contexto francês, busca tomar em consideração a realidade das mundanças intra e extra eclesiais.

Nesse artigo, temos por objetivo apresentar os elementos que permitem efetivamente afirmar a Teologia da Libertação (TdLib) como TPr, a partir do diálogo com o pensamento do teólogo francês Henri Bourgeois, que conjuga em suas obras duas características marcantes: a primeira faz referência ao conhecimento profundo da TPr, como representante da Escola de Lyon e segunda se refere ao largo conhecimento, ao interesse e à consideração dos elementos metodológicos da TdLib em sua reflexão para a TPr.

\section{Henri Bourgeois}

\subsection{Situação Histórica}

Nascido em Roanne (França) em 1934, Henri Bourgeois realiza sua formação acadêmica e sacerdotal vinculado à Diocese de Lyon, onde viveu até 2002, quando morreu aos 68 anos. Ali, desenvolveu, desde 1967, sua carreira acadêmica na Universidade Católica de Lyon como professor e em 1979 é eleito Diretor da Faculdade de Teologia.

Podemos afirmar que Bourgeois associou seu trabalho acadêmico ao pastoral, seja no desenvolvimento da formação catecumenal em sua Diocese, seja no âmbito das comunicações e da preocupação da evangelização pelos meios de comunicação, onde cria em conjunto com a Faculdade Protestante de Genebra, o Grupo Internacional e Ecumênico Mediathec (Médias et théologie de la comunication). Em 1987, funda juntamente com outros teólogos francófonos, a Societé International de Théologie Pratique (SITP).

$\mathrm{Na}$ mesma linha de abertura ao diálogo e a realidade, Bourgeois cria em 1990, o Espace Saint-Marie, que se converterá, em Lyon, na referência de espaço para o diálogo com outras denominações religiosas que se expandiam em França.

Finalmente, entre os anos 1993-2000 cria e dirige a Coleção DDB- Pascal Thomas - Práticas cristãs, onde são publicados 21 livros com temas tratados a partir da perspectiva da $\operatorname{TPr}^{1}$.

\footnotetext{
${ }^{1}$ Utilizaremos as siglas: TPr para Teologia Prática e TdLib para Teologia da Libertação.
} 


\subsection{Teologia de fronteiras}

Chamamos a teologia de Bourgeois de "teologia de fronteira", uma vez que sua formação e produção teológica acontecem em um momento chave para a redefinição da teologia, marcado pelo Concílio Vaticano II. Apesar de sua formação pré-conciliar, nosso autor desenvolve sua produção teológica logo após o Concílio. Influenciado positivamente pelos acontecimentos de Maio de 1968, sua primeira publicação ${ }^{2}$ é dedicada à questão dos diáconos permanentes, tema tratado no Concílio.

A década de 1960 é representada por transformações que trás consigo novas possibilidades de ação. Para a Igreja foi uma década decisiva, uma vez que se rompe a clausura institucional e se passa à recepção das ideias advindas do Vaticano II. Bourgeois é um dos teológos que consegue dar um passo à frente, entrando nessa nova dinâmica do fazer teológico.

Adotando uma metodologia efetivamente indutiva, muitos de seus livros são escritos a partir da escuta dos atores eclesiais e sociais. A partir da prática efetiva, de opiniões que recolhia anonimamente de cristãos e cristãs ou de pessoas interessadas ao tema que investigava ${ }^{3}$. Em sua escrita tem a preocupação de adequar o tema trabalhado ao pensador que melhor o aprofunda, seja por convicção, seja por investigação pessoal, seja por trabalhos realizados em colaboração ou pelas influências recebidas em sua formação.

\subsection{A TPr segundo Henri Bourgeois}

A diversidade de temas trabalhados por Bourgeois nos permite dizer que sua obra não trata somente da TPr em sentido estrito "técnico", efetivamente a prática e o vínculo com a realidade é uma característica de sua obra. Royon afirmará que para Bourgeois, não é possível dissociar a dogmática da teologia prática e menos ainda a experiência da conversão e da fét. Em sua obra a expressão da TPr, está diretamente ligada a seu trabalho pastoral.

Por consequência, sobre sua teologia, igualmente podemos afirmar que é contextualizada em dois sentidos. Primeiramente por ser realizada a partir de um contexto determinado, e em segundo porque se preocupa em lhe propor ações. Em seu caso, no contexto francês onde viveu.

\footnotetext{
${ }^{2}$ SCHALLER, R. e Bourgeors, H. Nouveau monde, noveaux diacre. Paris: Desclé, 1968.

${ }^{3}$ Cf. CASELLAS I MATTAS, J. Una teologia attenta a l'actualitat, p.69.

${ }^{4}$ Cf. BOURGEOIS, H. Intelligence et passion de la foi, p. 89.
} 
Contudo, a reflexão sobre a TPr não é alheia ao seu pensamento. A partir do Seminário da Faculdade de Teologia de Lyon, animado por Bourgeois nos anos de 1991/1992, ele escreve as conclusões sobre o título de Théorie et pratique 5 . Segundo, G. Routhier, esse texto vem dentro do propósito de uma reflexão de fundo perseguida durante anos, sobre a função teológica, seu exercício, suas produções e questões ${ }^{6}$. Refletindo ainda sobre as questões que envolvem teologia e prática, Bourgeois nos deixa em legado, um texto manuscrito localizado nos arquivos da Faculdade de Teologia de Lyon. Publicado em 2010 com o título de Questions Fondamentales de Théologie Pratique $^{7}$, que foi tomado como principal texto para nossa pesquisa.

\section{a. As dificuldades da Teologia em contexto francês}

Bourgeois parte de um questionamento mais amplo que toca ao sentido e à utilidade da Teologia mesma, para em segundo momento refletir sobre as questões da TPr em contexto francês. A questão que se apresenta inicialmente é a marginalidade da Teologia, seja no contexto social, seja no contexto eclesial.

Para o contexto social, nosso autor toma em consideração as grandes modificações sociais e de paisagem $^{8}$ como uma das causas para que a teologia na França se encontre em dificuldades. Há, segundo ele, um descrédito generalizado do trabalho teológico que pode mesmo afetar o futuro do cristianismo. Essa mesma perspectiva é refletida por Jacques Audinet de maneira mais ampla, ao questionar as razões internas para o desaparecimento da religião na sociedade francesa9 ${ }^{9}$.

Ora, para Bourgeois, a Teologia é mal considerada nos ambientes intra e extra eclesial. As comunidades cristãs têm poucas necessidades teológicas ou

\footnotetext{
${ }^{5}$ Texto conservado no Fundo Henri Bourgeois, na Université Catholique de Louvain.

${ }^{6}$ Cf. ROUTHIER, G. "Présentation", p. 5. In : Bourgeors, H. Questions fondamentales de Théologie Pratique (Collection Les Fondamentaux, 2). Montréal-Bruxelles : Novalis-Lumen Vitae, 2010.

${ }^{7}$ BOURGEOIS, H. Questions fondamentales de Théologie Pratique (Collection Les Fondamentaux, 2). Montréal-Bruxelles: Novalis-Lumen Vitae, 2010.

${ }^{8}$ Cf. BOURGEOIS, H. "Une place pour la pensée théologique". Revue Études 370 (1989), p. 647; Id. "Des places vides au colloque". Journal La Croix, 05 diciembre 1992, p. 23; Id. "La Théologie Française et l'Europe". Journal La Croix, 02 abril 1992, p. 26, onde denuncia ainda a centralização da Teologia Francesa nas Escolas de Paris.

${ }^{9}$ Cf. AUDINET, J. “Une culture sans religion?”. In: Audinet, J. Écrits de Théologie pratique. Paris: Cerf, 2005, pp. 81-87.
} 
não são preparadas e motivadas para debates teológicos reais e prolongados, argumentados e portadores de consequências ${ }^{10}$.

Contudo, nosso autor questiona também a rejeição da Teologia em contexto eclesial. Por um lado está a dificuldade dos próprios cristãos que passam ao lado da Teologia. Por medo de questionar a própria fé, mantémse na perspectiva da meditação e da aprendizagem das homilias ${ }^{11}$. Por outro lado, está a relação entre autoridades eclesiásticas e fiéis. A teologia é posta em causa por ambos e as contestações se reforçam mutuamente, seja pelo binômio autoridades $\mathrm{x}$ teólogos, onde os primeiros tentam reduzir a reflexão dos segundos, seja pelo binômio autoridades x fiéis, onde os primeiros ao oferecer uma reflexão acabada, anulam o papel mesmo da teologia.

Para o autor, é essencial que o pensamento teológico não seja jamais desconectado totalmente do contexto onde se realize e do status das pessoas que o reflitam, independentemente dos problemas de objetividade que uns e outros possam expressar. Nesse sentido, afirmamos que em analogia à expressão de Claude Geffré ${ }^{12}$, que Bourgeois trata do segundo silêncio ${ }^{13}$ da Teologia em França. Finalmente, é a partir da perspectiva do silêncio e da marginalidade teológica que Bourgeois repensa a questão da TPr.

\section{b. As duas perspectivas de análise de Bourgeois}

Ora, é a partir dessas questões de base que Bourgeois desenvolve sua reflexão. $\mathrm{Na}$ análise realizada em seu texto, afirmamos que a realiza, estabelecendo dois sentidos ${ }^{14}$. O primeiro, que chamamos de sentido geral, que faz referência aos critérios que o autor desenvolve para que uma teologia seja efetivamente considerada como TPr, e o segundo que chamamos de sentido especifico, que faz referência à compreensão de ação considerada por Bourgeois.

Ainda que sejam relacionados, para cumprir nosso objetivo nesse texto, deter-nos-emos especificamente ao primeiro sentido.

\footnotetext{
${ }^{10}$ Cf. BOURGEOIS, H. Questions fondamentales de théologie pratique, p. 10.

${ }^{11}$ Cf. BOURGEOIS, H. Une place pour la pensée théologique, p. 648.

${ }^{12}$ Cf. GEFFRÉ, C. Silence et promesses de la théologie française, p. 333.

${ }^{13}$ A expressão segundo silêncio, é de mina criação, que utilizamos para definir a situação de fundo de qual fala Bourgeois.

${ }^{14}$ Importante ressaltar que a identificação dos dois sentidos e sua nomenclatura, não são de Henri Bourgeois. Foram criadas por mim, para apresentar de forma mais clara a linha de pensamento do autor.
} 
O aporte da teologia de Bourgeois guarda relação com os teólogos de seu tempo, que ele naturalmente conhece e não ignora. Tendo um acento marcado pela apresentação não sistemática da fé cristã, busca aproximar-se das realidades vividas da existência cristã para refletir os elementos essenciais da TPr.

Primeiramente destaca a necessidade da correlação entre fé e experiência humana, buscando na primeira as proposições à segunda. Nesse sentido, inscreve-se no grupo de teólogos do pós-concílio que buscam, saindo do modelo apologético, revelar uma postura onde o teólogo reúne as demandas que se apresentam de crentes e não crentes, tentando responder-lhes a partir do conteúdo da fé revelada, de diferentes maneiras de acordo com o aspecto solicitado, e não a partir de uma realidade monolítica. Para nosso autor, o método de correlação entre Revelação e as questões existenciais não se situa somente em nível dos discursos instituídos, senão que está, sobretudo, no nível das experiências da vida cotidiana, que incluindo a subjetividade permite ao ser humano construir a si mesmo e à história.

Para Bourgeois, a "TPr é uma teologia das práticas"15. O que a teologia havia feito até o Vaticano II, era estabelecer relação com os discursos segundos, das ciências sociais através do diálogo direto entre ambas. Bourgeois, ao colocar uma distância reflexiva em relação às práticas da existência vivida, inclina-se por uma TPr que mostre a correlação entre Revelação e fé vivida e praticada através das ações cotidianas.

Nesse sentido, e em decorrência do já dito, a TPr deve aproximar-se da auto-compreensão de seus atores para aprender a inteligibilidade em ato. Esta deve tornar-se reflexiva, no sentido de aportar um discurso sobre a prática que lhe amplie seu sentido. De outra forma, podemos dizer que o que se espera é que a aproximação da prática leve a um desvelamento/descobrimento de um significado mais amplo que seu objeto e é sobre esse significado que se desvela que a TPr deve estabelecer um diálogo.

Nesse sentido, Boureux afirma que Bourgeois busca primeiramente encontrar o sentido da inteligibilidade do vivido ${ }^{16}$ ou seja, primeiramente

${ }^{15}$ Cf. BOURGEOIS, H. Questions fondamentales de théologie pratique, p. 46.

${ }^{16} \mathrm{Cf}$. BOUREUX, C. "La théologie pratique, une recherche de médiations". In: Actes du Colloque D'Eveux: Henri Bourgeois: Une théologie en dialogue dans les mutations culturelles. Lyon: AHB, 2011, p. 30. 
a compreensão das motivações e comportamentos dos atores sociais para posteriormente pensar a TPr mesma. Por essa razão o acompanhamento dos atores sociais, para ele, é central. Estando diretamente ligada a seus destinatários e acompanhando-lhes sua reflexão tem condições de aportar-lhes uma abertura e coerência na compreensão de seus atos. Por isso o teólogo prático não pode ser um "prescritor" de ações, senão que esse se insere dentro da realidade social construída ou em construção para realizar um discurso que dê novos caminhos à ação, que deverá ter sua eficácia verificada a posteriori.

Por consequência, Bourgeois advoga por uma TPr que rompa com a antiga prática apologética ao mesmo tempo que tome distância de uma teologia hermenêutica. No que tange à questão apologética, a razão está em que a TPr não produza um discurso que deva ser aplicado à realidade. A visão é justamente sair da bipolarização agostiniana (do compreender para crer e crer para compreender), mostrando que a prática é em si mesma racional e lugar teológico e que a teoria somente pode ser sustentada em relação com o real. Deve situar-se no terreno e no nível dos fatos mais que no registro dos pensamentos.

No que tange à hermenêutica, a razão está em que a TPr não garanta uma hermenêutica do corpus constituído, mas uma hermenêutica da prática em ato. É ela que permite descrever o tipo real aos discursos aos quais se refere. Por ela, pode-se mostrar que a produção do discurso teológico depende da compreensão da situação ao qual se vincula e seus destinatários. A hermenêutica abre as diferentes possibilidades de realização de uma teologia de maneira prática.

Finalmente podemos dizer que a consideração de uma teologia com TPr para nosso autor demanda três pontos essenciais: 1) a proximidade com os atores sociais para a compreensão da connassaince pratique ${ }^{17}$, o que dá racionalidade à ação; 2) a emissão do discurso teológico a partir da realização da ação e finalmente 3) a verificação da eficácia do discurso emitido, tomando as novas ações como instâncias críticas.

Ora, por não encontrar na TPr Francesa essa dinâmica teológica, que Henri Bourgeois se abre à análise de outras formas do fazer teológico que pudessem levá-la ao cumprimento de seu papel. Nesse momento considera as teologias desenvolvidas em contexto americano, em especial a TdLib.

\footnotetext{
${ }^{17}$ Cf. BOURGEOIS, H. Questions fondamentales de théologie pratique, p. 31, nota 5. No corpo do texto guardamos a expressão original "connaissance pratique" por acreditar que ela reflete um sentido mais amplo que a expressão em Português.
} 
Diferentemente da TPr canadense que se estabelece diretamente na academia, e por essa razão busca imediatamente seu estatuto epistemológico para se sustentar frente às outras ciências, e da teologia norte-americana, que se estabelece a partir de uma pluralidade de linhas teológicas de origem européia $^{18}$, é na TdLib que Bourgeois encontra uma contribuição à TPr Francesa.

\subsection{A contribuição da TdLib à TPr Francesa}

É na proximidade com a realidade que realiza a TdLib, que Bourgeois encontra o ponto positivo de contribuição entre as duas linhas teológicas.

Contudo, é importante ressaltar que não se trata de uma questão comparativa ou de copiar essa teologia ao contexto francês, senão que uma questão de contribuição real entre duas correntes teológicas de forma que a TPr Francesa avance a partir do que ele considera essencial: a aproximação entre Teologia e os atores sociais. Nosso autor considera que a TdLib, consegue articular as duas perspectivas essenciais à TPr: aproximar a teologia para responder às demandas da sociedade, mediante a ação e o discurso teológico, através do fundamento Evangélico.

Para ele, a forma prática de fazer teologia dessa corrente teológica mudou profundamente as perspectivas da $\operatorname{TPr}^{19}$. A TdLib não se aproxima nem da $\mathrm{TPr}$ original alemã nem da Teologia Pastoral francesa. Afirmará Bourgeois:

Essa teologia latino-americana, aquela de Gustavo Guitérrez, Leonardo Boff, e Juan Luis Segundo, se aproxima à TPr de origem alemã ou a do estilo pastoral francês? De fato, ela é outra e se vê sem referências obrigatórias às teologias européias que certamente ela não ignora. Ela se vê ligada ao seu próprio contexto, o que ela exprime insistindo sobre sua "contextualidade" 20 .

Para Bourgeois, o que marca a TdLib é, primeiramente, sua relação com o povo, em especial os reunidos em comunidades vivas e que têm relativa

\footnotetext{
${ }^{18}$ ROUTHIER, G. "Le Canada francophone”. In: Joseph Doré (dir.). Le devenir de la théologie catholique mondiale depuis Vatican II - 1965-1999. Paris: Beauchesne, 2000, pp. 259-317; e Dulles, A. "Les États-Unis". In: Joseph Doré (dir.). Le devenir de la théologie catholique mondiale depuis Vatican II - 1965-1999. Paris: Beauchesne, 2000, pp. 319-338.

${ }^{19} \mathrm{Cf}$. BOURGEOIS, H. Questions fondamentales de théologie pratique, p. 14.

${ }^{20} \mathrm{Cf}$. BOURGEOIS, H. Questions fondamentales de théologie pratique, p. 14.
} 
influência eclesial e social. Desse ponto de vista, essa teologia não tem como prioridade a obtenção de um estatuto universitário reconhecido dentro do campo dos conhecimentos. Seu reconhecimento dá-se articulando-se a práticas locais efetivas ${ }^{21}$.

Por isso essa Teologia não teve como primeira preocupação a definição metodológica ou estatutária: sua preocupação esteve antes orientada a conhecer as condições do contexto na qual se encontrava. Nesse contexto os interesses de um grande público são bastante precisos e têm um caráter de emergência. Estas não são experiências mais ou menos objetivas a ser analisadas, e menos ainda estados de alma. Estes interesses são exigências históricas e proféticas ${ }^{22}$.

O ponto-chave da TdLib é o passo anterior de seu fazer teológico, que pode ser traduzido na eleição de primeiramente compreender o interesse e as necessidades de seu grande público, como estes devem ser trabalhados e quais são os resultados concretos que a Teologia mesma pode oferecer a seu favor e de sua realidade. Somente a partir da compreensão das demandas efetivas da realidade que a TPr pode atuar e realizar um discurso coerente sobre as práticas.

Seguindo essa reflexão, complementa Bourgeois:

O problema da teologia européia e em particular a francesa, não seria de identificar quais são hoje, dentro do espaço que é o seu, os desafios aos quais a população dentro de seu conjunto é afrontada às questões que as Igrejas podem mal conhecer? Em outros termos: a qual emancipação a teologia pode ajudar? E em quê uma teologia prática pode ela contribuir à qualidade de vida e à realidade da fé na Europa ${ }^{23}$

${ }^{21}$ Cf. BOURGEOIS, H. Questions fondamentales de théologie pratique, p. 14. Em nossa opinião essa citação de Bourgeois descreve a sua maneira, o que é uma Cebs. Aqui demonstra seu amplo conhecimento da TdLib. Além de ser contemporáneo de Gustavo Gutiérrez en Lyon e participar de sua Banca de Doutorado, Henri Bourgeois, realiza uma viagem de três meses ao Brasil no final dos anos 70, para conhecer a realidade da Igreja Brasileira e a forma de trabalho das Cebs no Nordeste do Brasil. Nessa viagem encontrou-se com três grandes representantes da TdLib: D. Antonio Fragoso, (Crateús), D. Aloisio Lorscheider (Fortaleza), y D. Helder Camara, (Recife-Olinda), que muito lhe impressionou segundo relato do Padre Claude Marechal (Assumpcionista de Valpré Écully; France em entrevsista realizada em Lyon, 04/11/2011), que o acompanhou nessa viagem.

${ }^{22}$ Cf. BOURGEOIS, H. Questions fondamentales de théologie pratique, p. 63.

${ }^{23}$ Cf. BOURGEOIS, H. Questions fondamentales de théologie pratique, p. 64. 


\section{A TDLıs segundo Bourgeois. Articulações metodológicas e teológicas}

Bourgeois demanda a TPr de ser uma teologia "concreta, próxima e prática ${ }^{24 "}$ recentrando-se sobre a experiência da ação que trás nela mesma uma "connaissance pratique", com o papel de dar à ação uma "nova inteligibilidade" e poder verificar sua eficácia: ele não especifica um método para se aproximar da ação, uma vez que em sua opinião, mais importante que o método a ser utilizado é tomar em consideração a ação e sua realidade.

De mesma forma, não há de sua parte uma especificação da ação. Ora, se de uma parte não especificando a ação, Bourgeois arrisca-se a comprometer o método a ser utilizado e a emissão de um novo discurso teológico, de outra parte, ele se permite buscar fora de seu contexto uma teologia que poderia indicar possibilidades dessa especificação e proximidade com a realidade. É nesse sentido que ele toma em consideração a TdLib.

$\mathrm{Na}$ análise de seu método da TdLib encontramos elementos que respondem a suas proposições e reivindicações. Se Bourgeois indica o que deve ser realizado, a metodologia da TdLib demonstra como e o que deve ser realizado: as ações de libertação. Nossa posição é de que é essa especificação da ação, a contribuição da TdLib à reflexão de Henri Bourgeois.

\section{a. Reflexões metodológicas e teológicas}

Tomando em consideração o sentido geral da teología de Bourgeois, aquele que especifica as condições para que uma teologia seja considerada efetivamente como teologia prática, apresentamos os quatro pontos chaves de seu pensamento, que encontramos ser coerentes para a afirmação da TdLib como TPr.

\subsection{A conexão com a ação}

Segundo Bourgeois, o fato de que uma teología comporte uma vertente prática não lhe garante o estatuto de TPr. Antes, essa deve necessariamente: 1) estar vinculada de forma prioritária às práticas eclesiais e sociais; 2) entrar em debate com as outras formas de fazer teológico, apresentando um método relativamente definido, e por último 3) articular-se a uma demanda que

${ }^{24}$ Cf. BOURGEOIS, H. Questions fondamentales de théologie pratique, p. 11. 
responda não somente ao povo cristão, senão que seja capaz de atender a toda a sociedade . $^{25}$.

Sabemos que a relação entre Teologia e práxis não é exclusiva da TdLib. Toda teologia se relaciona com a prática, inclusive se não se percebe de maneira explícita. A TdLib não se coloca como antítese frente a isso, como se ela fosse essencialmente prática e as demais teóricas ${ }^{26}$.

Nesse sentido, as diferenças entre as teologias práticas podem ser vistas em torno a dois pontos essenciais: 1) como a teologia situa a prática em seu fazer teológico e 2) em que constitui efetivamente essa prática.

Em relação à TdLib, afirmamos que essa se constitui como TPr não somente porque desde sua etapa de Gestação guarda um vínculo estreito com a prática pastoral e social, senão porque a partir desse vínculo determina sua nova forma de fazer teologia ${ }^{27}$, que permite a especificação da ação e a forma como se relaciona com essa.

A especificação de sua prática vê-se no próprio nome: é prática de libertação dos pobres. Essa foi constituída a partir de dois aspectos: 1) a influência que recebe dos movimentos teológicos dos anos pré conciliares e pelas novidades afirmadas pelo Concílio Vaticano II (a ressignificação da história, a reaproximação entre Igreja e mundo, a mudança eclesiológica e a centralidade dos pobres), o que se traduz e se realiza de forma contextualizada na América Latina, e 2) sua constituição histórica: a TdLib nasce de uma atividade pastoral concreta que reconhece a realidade da pobreza institucionalizada no continente. É a partir da proximidade com a realidade e da inserção eclesial que se estabelece a eleição dos pobres como eixo central dessa teologia.

A novidade e a diferença que marcam a TdLib é que ao Ver a realidade latino-americana e se deparar com a pobreza instituída, assume o homem pobre latino-americano como seu "sinal do tempo" central. Ele é a categoria teológica que permite projetar a ação da Igreja na História, vertente históricopastoral, e a presença de Deus na História, vertente histórico-teologal. Tratase de responder teologicamente a uma situação real e concreta em que se encontrava a maior parte dos cristãos, que nem de longe era reflexo de um continente evangelizado.

${ }^{25}$ Cf. BOURGEOIS, H. Questions fondamentales de théologie pratique, p. 61.

${ }^{26}$ Cf. FLORISTÁN, C. Teología Práctica. Teoría y Praxis de la acción pastoral. Salamanca:

Sígueme, 2009, p. 138.

${ }^{27}$ Cf. FLORISTÁN, C. Teología Práctica. Teoría y Praxis de la acción pastoral, p. 138. 
Nesse sentido, a prática da TdLib nasce de uma experiência primeira (traduzida na centralidade do pobre), que se faz junto àqueles que demandam à teologia respostas concretas às suas realidades. Essas respostas se convertem no discurso teológico que vem como experiência segunda.

As experiências práticas que realiza são balizadas pela experiência mesma de Jesus e seu seguimento, e por essa razão espera-se que essas visem à implementação de sinais do RD no presente da História. Ortodoxia e ortopraxia unem-se através da hermenêutica do pobre, rompendo com a abstração genérica da ação e com centralização da teologia sobre si mesma.

Por isso, podemos afirmar que a TdLib não é somente uma teologia que atua sobre a prática, senão que é para e a partir dela, da mesma forma que solicita àqueles que a realizam sua inserção na prática e no contexto ${ }^{28}$. Essas são práticas históricas e encarnadas. Não se faz TdLib colocando-se ao exterior do contexto que se pretende responder. Justamente por estar inserida e ter a preocupação primeira pela prática, que essa teologia mantém a aproximação com as pessoas.

\subsection{A centralidade dos atores sociais}

O segundo ponto é a centralidade dos sujeitos (atores sociais) na TPr. Esses são considerados ao mesmo tempo como sujeitos e destinatários da teologia. Bourgeois considera que os sujeitos não são independentes ou autônomos de sua ação e, que a teologia tem o desafio e a responsabilidade de incentivá-los à ação ${ }^{29}$. Por isso, para nosso autor a TPr não se situa no nível dos discursos constituídos, senão que se encontra no nível das experiências da vida cotidiana ${ }^{30}$.

Em consequência, dirá Bourgeois, uma TPr é “das práticas” em condições bastante claras: que não se feche dentro dos discursos de seus responsáveis;

${ }^{28}$ Cf. BOURGEOIS, H. Questions fondamentales de théologie pratique, pp.19-20. Em nossa opinião, nesse ponto encontra-se a grande diferença entre a Teologia realizada por Bourgeois e a TdLib. A segunda tem seu desenvolvimento a partir da prática. Esse é um dos pilares de sua constituição. Ao passo que a teologia desenvolvida por Bourgeois como a Catequese ou a Pastoral dos Recommençants atua sobre o contexto. Por outro lado, Bourgeois demanda à TPr o que faz a TdLib: a atuação a partir, por e pela prática, afirmando que Prática é a teologia que deve "ir às ruas".

Cf. Scannone, J.C. "Liberación, Teología de la." In: Floristán, C. e Tamayo, J.J. Conceptos Fundamentales de Pastoral. Madrid: Editora Cristandad, 1983, p. 567.

${ }^{29}$ Cf. BOURGEOIS, H. Questions fondamentales de théologie pratique, p. 77.

${ }^{30}$ Cf. BOURGEOIS, H. Questions fondamentales de théologie pratique, p. 46. 
que entre os sujeitos implicados se desenvolva uma rede de relações que lhes una; que se posicione, às vezes, no terreno dos movimentos institucionais; e que não se esqueça que seus atores são portadores de uma identidade pessoal, que jamais é plenamente assimilada por sua situação social e comunitária ${ }^{31}$. Para Bourgeois essa é a função primeira da Teologia: estabelecer contato com as pessoas que esperam uma resposta teológica ${ }^{32}$.

Ora, a TdLib encontra sua singularidade frente às demais $\operatorname{TPr}(\mathrm{s})$ em sua reconhecida ação pastoral frente à urgência da realidade em que se encontra. O hiato entre a TdLib e as demais teologias da prática, não se dá no mundo das idéias, mas no mundo real onde as pessoas vivem, morrem e esperam.

Em última instância, afirmar a prática de libertação dos pobres é afirmar a fundamentação cristocêntrica, sua opção teocêntrica e profética, sua realização e percepção da história, sua contextualização com vistas a um objetivo definido: a esperança da implantação do Reino de Deus (ou seus sinais) no Já da história.

Dessa forma, os pobres como sujeitos da libertação e primeiros destinatários da Palavra de Deus como expressado na prática de Jesus, podem experimentar em seu processo histórico, de forma antecipada, o prometido para o Ainda Não. Nesse sentido, encontramos o segundo caráter específico da prática libertadora: são ações realizadas com vistas à transformação de uma determinada realidade social ${ }^{33}$.

\subsection{A liberdade metodológica}

O terceiro ponto se refere à forma memorável em que Bourgeois advoga por uma liberdade metodológica. Para ele a credibilidade de uma teologia que se relaciona com a prática, não vem de seu método, senão pela forma como essa a considera. Essa credibilidade está na liberdade com que mantém contato com a prática, buscando entendê-la para dar-lhe respostas às suas demandas. Nesse sentido, a sistematização é livre ${ }^{34}$. Bourgeois não afirma que o método não seja necessário, mas se esse é presente, sua função deve ser ajudar a teologia a aproximar-se da prática e de seus atores sociais.

\footnotetext{
${ }^{31}$ Cf. BOURGEOIS, H. Questions fondamentales de théologie pratique, p. 50.

${ }^{32}$ Cf. BOURGEOIS, H. Questions fondamentales de théologie pratique, pp. 19-22. ${ }^{33} \mathrm{Cf}$. AQUINO JÚNIOR, F. Teoria Teológica. Práxis teologal. Sobre el método da Teologia da Libertação. São Paulo: Paulinas, 2012, p. 129.

${ }^{34}$ Cf. BOURGEOIS, H. Questions fondamentales de théologie pratique, p. 53.
} 
Na constituição da TdLib, a urgência da resposta histórica e teológica à realidade latino-americana, deslocou o teórico a um momento segundo. Contudo a TdLib participa das regras sintáticas comuns a todas as teologias, guardando regras próprias quanto à relação com as práticas de libertação.

Ainda que Medellin assuma a tradição e a inspiração do método V-J-A(verjulgar-agir), iniciado pela Ação Católica de Cardjin e adotada na constituição GS, a TdLib constitui um método próprio, uma forma própria de relacionar-se com a realidade e com a prática: esse método visa a sua transformação. Para tanto, estabelece como base de sua metodologia três sólidos parâmetros: 1) a prioridade da prática sobre a teoria e por conseqüência a indutividade de seu fazer teológico; 2) a consideração da história e de toda a realidade; 3) as mediações das ciências sociais, hermenêutica e filosofia em sua realização.

A centralidade da prática na TdLib não é somente uma postura de relacionar-se com ela, senão também dar-lhe um sentido transformador da realidade. Por isso, é essencial partir de uma hermenêutica dialética que busque sentido transformador para a prática, para sua operatividade social à luz da revelação em um processo histórico de dominação.

Ressignifcar a tradição dada no contexto presente faz com que a prática provoque uma nova interpretação da tradição, ao mesmo tempo em que essa ilumina a prática. Nesse sentido, não se trata de dar um sentido a uma realidade já existente, senão de transformá-la para que chegue a ter um sentido e dessa maneira recuperar o sentido da fé.

Nesse processo metodológico, abrem-se duas perspectivas de relação com a prática:

1) perspectiva teórica, que situa a ação em tanto que "matéria prima" de sua reflexão,

2) perspectiva prática, que define a situação do teólogo em relação à ação a partir de três momentos: a) na práxis ${ }^{35}$ : que revela a necessidade do teólogo de estar engajado na ação a qual trata; b) para práxis: que revela a intencionalidade de oferecer uma nova racionalidade à ação e c) pela práxi ${ }^{36}$ : que é a ação como instância crítica de eficácia da nova inteligibilidade aportada.

\footnotetext{
${ }^{35}$ Cf. LIBÂNIO, J. Panorama da teologia da América Latina nos últimos 20 anos. Revista Perspectiva Teológica 24 (1992), p. 155. A mesma pergunta de fundo faz Boff, Clodovis. Teología e Prática. A Teología do Político e suas mediações. Petrópolis: Vozes, 1978, p. 22.

${ }^{36}$ Cf. GUTIÉRREZ, G. Teología de la Liberación. Perspectivas. Lima: CEP, 1971, p. 28.
} 
Em nosso ponto de vista, essas três perspectivas respondem às demandas de Bourgeois: na práxis, responde-se à demanda de proximidade da realidade para compreender sua connaissance pratique; para práxis, responde-se à demanda de oferecer uma nova inteligibilidade que forja a realização de novas ações e, finalmente, pela práxis responde-se à demanda de compreensão da eficácia da teológica. Existe finalmente uma complementaridade entre as demandas de Bourgeois para a TPr e o método da TdLib que se revela através da relação com ação.

\subsection{A leitura da realidade}

O quarto e último ponto trata da honestidade científica e teológica com a qual a TPr deve considerar a prática e a realidade. Para Bourgeois, é fundamental não falsear a identidade da experiência prática racionalizandolhe ou teorizando abusivamente, seja de maneira abstrata ou excluindo a perspectiva dos atores que a realizam.

\subsection{A utilização das ciências na TdLib}

A reflexão sobre as novas formas de pensar teologia associada às ciências já permeava o pensamento dos padres conciliares. Em 1963, M.D. Chenu expõe sua preocupação sobre a importância de que a Teologia pudesse dar respostas eminentemente teológicas à realidade, apesar da utilização das categorias sociológicas para realizar sua leitura ${ }^{37}$.

$\mathrm{Na}$ Europa, a associação entre teologia e ciências, generalizada no fim dos 60, permite a G. Adler ${ }^{38}$ classificar a segunda etapa da construção da Teologia Prática francesa como aquela marcada pela utilização das ciências humanas, particularmente a sociologia e psicologia que ofereciam uma maneira não dogmática de conhecer, descrever e dar significação à prática eclesial.

\footnotetext{
${ }^{37}$ Cf. CHENU, M.D. "Tradition et Sociologie de la Foi”. In: Betz, Johannes ; Fries, Heirich (org.). Église et Tradition. Lyon : Éditions Xavier Mappus, pp. 225-232.

${ }^{38}$ Cf. ADLER, G. Questions de Théologie pratique dans l'aire francophone catholique. Revue des sciences religieuses 69 (1955), p. 280. Adler considera três etapas: 1) Anos 50: Fase pastoral; 2) Anos 60-70: associação às Ciências Humanas e 3) A partir dos anos 70: a afirmação da separação e o deslocamento da Teologia Pastoral, centrada nas atividades intra-eclesiais (catequese, liturgia, missiologia) à Teologia Prática propriamente dita, centrada na ação da Igreja que se relaciona com as ações de cristãos e não cristãos, em um contexto sócio-cultural que se transforma continuamente e chega às academias francesas.
} 
Ora, a origem da TdLib insere-se dentro do contexto de deslocamento de parâmetros do fazer teológico. Com efeito, essa se compreende desde o princípio, como no dizer de Brighenti ${ }^{39}$, como uma omniteologia; marca a independência de seu fazer teológico. É nesse sentido que Gutiérrez vai afirmar uma nova forma de fazer teologia que realiza a inversão hermenêutica. Não se trata somente de realizar a função crítica da ação pastoral da Igreja, senão a reflexão crítica da praxis histórica à luz da Palavra ${ }^{40}$. Tendo por base o método jocista V-J-A, propõe-se realizar uma reflexão crítica "a partir de" e "sobre" a práxis histórica em confrontação com a Palavra.

Por isso, ela se diferencia da Teologia Escolástica por partir de uma razão indutiva e da Teologia Moderna, por buscar não mais um sentido para o sentido da existência humana, senão que por buscar o sentido para a práxis histórica. Não se trata mais de dar sentido a uma prática já existente, senão de transformar a realidade para que esta alcance seu sentido e dessa maneira poder recuperar o sentido da fé. O que a TdLib estabelece é um discurso de ruptura com a realidade existente e se aponta para o novo. Deixa de ser uma teologia que trata da morte de Deus, para tratar da vida dos homens.

Ora, as práticas de libertação estão condicionadas pelo contexto e por isso, exigem sua compreensão de forma científica. Por essa razão, a TdLib busca auxílio em outras ciências postas como mediações para compreensão da realidade. São mediações porque cumprem o papel de mediar teoricamente a realidade humana e o conhecimento teológico.

Assim, se desvela em seu método a utilização da MSA (mediação sócioanálitica) e a MH (mediação hermenêutica) como opções teóricas que auxiliam a reflexão sobre a prática. $\mathrm{O}$ reconhecimento da realidade e sua compreensão reforçam o primeiro ponto de seu método de inspiração: o Ver, que iluminado pela Palavra de Deus lida em Igreja (Julgar), gera a prática libertadora (Agir).

Considerando as mediações e relacionamento com as ciências que formaram a metodologia da TdLib, podemos afirmar que essa se localiza "entre" a classificação ${ }^{41}$ Multi-disciplinar e Intra-disciplinar. Especificamos "entre", porque a TdLib utiliza as MSAs guardando a preocupação com a

\footnotetext{
${ }^{39}$ Cf. BRIGHENTTI, A. Raizes da epistemologia e do método da Teologia da Libertação. O método Ver-Julgar-Agir e as mediações da Teologia Latino Americana. Louvain-la-Neuve: Université Catholique de Louvain, p. 21.

${ }^{40}$ Cf. GUTIÉRREZ, G. Teología de la Liberación. Perspectivas, p. 38.

${ }^{41}$ Cf. VAN DER VEN, G. Practical Theology: an empirical approach. Leuven: Peeters Press, 1998, (3 Edition), pp. 89-112.
} 
autonomia da Teologia mesma para emitir o parecer teológico, mas dá um passo à frente ao incorporar em sua metodologia e fazer teológico, termos e formas de análises vindos das ciências sociais, que sem prejuízo da seriedade teológica abrem a compreensão com a prática.

\section{Conclusão}

Diferentes autores afirmam que a TdLib pode ser considerada TPr, tomando em consideração somente sua proximidade com a prática ${ }^{42}$. Como apresentamos, quando nos referimos a TPr não se trata somente de examinar o como se aplica o saber teológico, mas também o porquê o aplica. Sua finalidade é dar conta da fé e de Deus, o que ela confessa no contexto das práticas sociais e culturais contemporâneas ${ }^{43}$. A resposta ao "como" e ao "porquê", vem da compreensão de dois pontos essenciais: 1) das diferentes formas pelas quais as teologias se relacionam e tomam em consideração as práticas e 2) o que é efetivamente essa prática.

Nesse percurso histórico-teológico-metodológico, o objetivo principal foi concentrado em explicitar a partir dos critérios de TPr de Henri Bourgeois, porque efetivamente a TdLib pode ser considerada TPr. Nós quisemos também demonstrar que a afirmação da TdLib como TPr não é uma eleição superficial, mas aquela que toma em consideração e exige a compreensão de sua constituição histórico-metodológica.

O percurso que escolhemos nos permitiu igualmente apresentar o autor francês Henri Bourgeois, que apesar de sua afinidade e interesse com a Teologia Latino-americana, ainda é pouco conhecido e trabalhado em nosso contexto.

Em definitivo, a TdLib é uma TPr por seu ponto de partida; percepção e análise da realidade miserável, produto de situações e estruturas sociais, econômicas e políticas injustas que produzem a indignação ético-religiosa

\footnotetext{
42 Podemos citar por exemplo quatro autores representativos da TPr: MARLÉ, R. Le projet de Théologie Pratique (Collection Le Point Théologique 32). Paris: Beauchesne, 1979, p. 125. Viau, M. Introduction aux études pastorales. (Collection Pastoral et vie 7). Montréal: Paulines, 1987, p. 66. Dulles, A. The assurance of things hoped for. A Theology of Christian Faith. Oxford: Oxford University Press, 1994, p. 177. Moltmann, J. Experiências da reflexão teológica, Caminhos e formas da teologia cristã. São Leopoldo: Unisinos, 2004, p.185.

${ }^{43} \mathrm{Cf}$. AUDINET, Jacques. "Théologie pratique et pratique théologique”. In: Audinet, Jacques; Chenu, Marie-Dominique ; Bellet, Maurice. Le déplacement de la théologie (Le Point Théologique 21). Paris : Beauchesne, 1979, pp. 91-107.
} 
e por seu ponto de chegada; fomento de uma prática social solidária com a esperança dos pobres em virtude de uma fé verdadeira e de uma caridade política, isto é, aquela com perspectiva totalizadora de libertação integral ${ }^{44}$. Finalmente, também é por seu discurso teológico mediador entre uma nova maneira de viver a fé e sua comunicação, já que a leitura, ou releitura do evangelho se faz com vistas ao anúncio de sua mensagem.

\section{Referências bibliográficas}

ADLER, Gilbert. 'Questions de Théologie pratique dans l'aire francophone catholique". Revue des sciences religieuses 69 (1955), pp. 277-291.

AQUINO JÚNIOR, Francisco. Teoria Teológica. Práxis teologal. Sobre el método da Teologia da Libertação. São Paulo: Paulinas, 2012.

AUDINET, Jacques. "Une culture sans religion?". In: AUDINET, Jacques. Écrits de Théologie pratique. Paris : Cerf, 2005, pp. 81-87.

AUDINET, Jacques. "Théologie pratique et pratique théologique". In: AUDINET, Jacques ; CHENU, Marie-Dominique, et Maurice.

BELLET. Le déplacement de la théologie (Le Point Théologique 21). Paris: Beauchesne, 1979, pp. 91-107.

BENTO XVI. Discurso de Inauguración de la $V$ Conferencia General del Episcopado Latinoamericano, 4, prononcé le 13 mai 2007. Disponível em: <www.aciprensa.com>. Acesso em 01 de fevereiro de 2013.

BOFF, Clodovis. Teología e Prática. A Teología do Político e suas mediações. Petrópolis: Vozes, 1978.

BOURGEOIS, Henri. Intelligence et passion de la foi. Paris : Desclée de Brouwer, 2000.

BOURGEOIS, Henri. Questions fondamentales de Théologie Pratique (Collection Les Fondamentaux, 2). Montréal-Bruxelles : Novalis-Lumen Vitae, 2010.

BOURGEOIS, Henri. "Une place pour la pensée théologique". Revue Études 370 (1989), p. 647.

BOURGEOIS, Henri. "Des places vides au colloque”. Journal La Croix, p. 23, 05 de dezembro 1992.

BOURGEOIS, Henri. “La Théologie Française et l'Europe” Journal La Croix, p. 26, 02 de abril 1992.

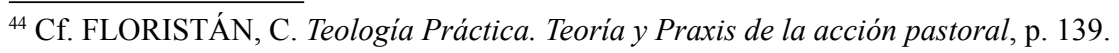


BOUREUX, Christophe. La théologie pratique, une recherche de médiations. In : Actes du Colloque D'Eveux: Henri Bourgeois: Une théologie en dialogue dans les mutations culturelles. Lyon: AHB, 2011, p. 31.

BRIGHENTTI Agenor. Raizes da epistemologia e do método da Teologia da Libertação. O Método Ver-Julgar-Agir e as mediações da Teologia Latino Americana. Louvain-la-Neuve: Université Catholique de Louvain, 1993.

CASELLAS i MATTAS, Josép. Una teologia attenta a l'actualitat. (Colección Lectânia Sant Paciá). Barcelon: Facultat de Teologia de Catalunya, 2011.

CHENU, Marie-Dominique. "Tradition et Sociologie de la Foi". In: Betz, Johannes; Fries, Heirich (org.). Église et Tradition. Lyon: Éditions Xavier Mappus, 1967.

DER VEN, Johannes van. Practical Theology: an empirical approach. Leuven: Peeters Press, 1998, (3 Edition).

DULLES, Avery. "Les États-Unis". In: DorÉ, Joseph (dir.). Le devenir de la théologie catholique mondiale depuis Vatican II - 1965-1999. Paris: Beauchesne, 2000, pp. 319-338.

DULLES, Avery. The assurance of things hoped for. A Theology of Christian Faith. Oxford: Oxford University Press, 1994.

DURAND, Jean Dominique. "La grande attaque de 1956". Cahiers Jacques Maritain, t. 30, 1995, pp. 2-31.

FLORISTÁn, Cassiano. Teología Práctica. Teoría y Praxis de la acción pastoral. Salamanca: Sígueme, 2009.

GEFFRÉ, Claude. "Silence et promesses de la théologie française". In: GREFFRÉ, Claude. Le christianisme au risque de l'interprétation. Paris: Cerf, 1977, pp. 323-346.

GUTIÉRREZ, Gustavo. Teología de la Liberación. Perspectivas. Lima: CEP, 1971.

JOURJON, Maurice. "Henri Bourgeois dans le souvenir". In: GondAL, MarieLouise. Henri Bourgeois Théologien de la nouveauté chrétienne. Lyon: Profac, 2006, p. 16.

LIBÂNIO, João Batista. "Panorama da teologia da América Latina nos últimos 20 anos". Revista Perspectiva Teológica 24 (1992), pp. 155-163.

LACROIX, Roland. "Le responsable pastoral". In: GondaL, Marie-Louise. Henri Bourgeois Théologien de la nouvaté chrétienne. Lyon: Profac, 2006, p. 30.

LEPRIEUR, François. Quand Rome condamne. Dominicains et prêtres ouvriers. Paris: Cerf, 1989. 
MARLÉ, René. Le projet de Théologie Pratique. (Collection Le Point Théologique 32). Paris: Beauchesne, 1979.

MOLTMANN, Jürgen. Experiências da reflexão teológica, Caminhos e formas da teologia cristã. São Leopoldo: Unisinos, 2004.

ROUTHIER, Gilles. "Présentation". In : BOURGEOIS, HENRI. Questions fondamentales de Théologie Pratique. (Collection Les Fondamentaux, 2). Montréal-Bruxelles: Novalis-Lumen Vitae, 2010.

ROUTHIER, Gilles. "Le Canada francophone". In: DORÉ, Joseph (dir.). Le devenir de la théologie catholique mondiale depuis Vatican II - 19651999. Paris: Beauchesne, 2000, pp. 259-317.

SAUVAGE, Pierre. Jacques Leclerq 1891-1971. Un arbre en plein vent. Louvain-la-Neuve : Duculot, 1992.

SCHALLER, René ; BOURGEOIS, Henri. Nouveau monde, noveaux diacres. Paris: Desclée, 1968.

SCANNONE, Juan Carlos. "Liberación, Teología de la". In: Floristán, Casiano; TAMAYO, Juan José. Conceptos Fundamentales de Pastoral. Madrid: Editora Cristandad, 1983, pp. 565-567.

SOUZA, Alzirinha. El análisis de la desconexión de sentido entre la Esperanza y la acción humana, a partir da obra de José Comblin. Louvain-laNeuve: Université Catholique de Louvain (UCL), 2014.

TRANVOUEZ, Yvon. Catholiques es communistes. La crise du progressisme chrétien. Cerf: Paris, 2000.

VIAU, Marcel. Introduction aux études pastorales. Collection Pastoral et vie 7). Montréal: Paulines, 1987.

Alzirinha Souza

Doutora em Teologia pela Université Catholique de Louvain Coordenadora do Curso de Pós-graduação Religião e Cultura - UNIFAI Vila Mariana / SP - Brasil E-mail: alzirinharsouza@gmail.com

Recebido em: 13/04/15

Aprovado em: 28/09/15 